\title{
Evaluation of non-traumatic intracranial hemorrhages as cause of cardiac arrest in emergency department
}

\author{
๑Mustafa Emin Çanakçı1 ${ }^{1}$, ๑Kübra Parpucu Bağçeci², ๑Engin Özakın¹, ๑Nurdan Acar ${ }^{1}$ \\ ${ }^{1}$ Eskișehir Osmangazi University, Department of Emergency Medicine, Eskișehir, Turkey \\ ${ }^{2}$ Yunus Emre State Hospital, Department of Emergency Medicine, Eskişehir, Turkey
}

Cite this article as: Çanakçı ME, Parpucu Bağçeci K, Özakın E, Acar N. Evaluation of non-traumatic intracranial hemorrhages as cause of cardiac arrest in emergency department. J Health Sci Med 2021; 4(4): 472-476.

\begin{abstract}
Aim: Cardiac arrests can be brought to emergency departments with an intervention from out-of hospital, and they can also occur for different reasons in the emergency department. Due to the high rates of mortality in this important clinical situation, regulations are made through guidelines and algorithms. Most of these regulations cover acute coronary syndromes and special conditions. The aim of our study is to evaluate intracranial hemorrhages in non-traumatic cardiac arrest cases in our emergency department for a period of 10 years.

Material and Method: The data of patients 18 years of age and over who were found to have cardiac arrest in the emergency department between January 2011 and January 2021, who did not have trauma, were retrospectively scanned from the hospital information management system. Demographic information of all patients, computed tomography examinations for intracranial hemorrhage and emergency department outcomes were evaluated.

Results: Of the 173 patients included in the study, 81 (46.8\%) were women. The median age of the patients was determined as 72.00 (IQR 64.00-80-00). In the whole patient group, 20 (11.6\%) patients had intracranial bleeding and 10 of these patients were women. More intrcranial hemorrhage was detected in the group that underwent CT before cardiopulmonary resuscitation (CPR) and it was statistically significant $(\mathrm{p}<0.001)$. In $4 \%$ of the patients who underwent CT after CPR, intracranial bleeding was detected. No difference was found in terms of the presence of bleeding or the timing of tomography in terms of discharge from the hospital.

Conclusion: With this study, we found the rate of intracranial hemorrhage (ICH) to be $11.6 \%$ in patients with in-hospital cardiac arrest. As changes occur in the treatment and management of patients in the presence of ICH, we think that brain CT should be performed in the early period in cardiac arrest cases of unknown cause, as stated in the guidelines. Especially in the presence of change in consciousness and high blood pressure, it is important to organize algorithms in order to detect ICH.
\end{abstract}

Keywords: Cardiac arrest, intracranial hemorrhage, emergency department

\section{INTRODUCTION}

Guidelines on Advanced Cardiac Life Support (ACLS) have suggested acute coronary syndromes as the cause of sudden cardiac arrest $(1,2)$. In addition to fatal dysrhythmias and acute coronary syndromes, intracranial hemorrhages (ICHs) may also cause arrests. However, the studies on their incidence are limited in number. This condition occurs in both pre-hospital and in-hospital settings, and it continues to be an important clinical condition in cardiac arrest(3). In the studies conducted, the incidence of ICH in out-of-hospital cardiac arrests (OHCA) was found to be approximately $4 \%$, while this rate was found to be $1 \%$ in in-hospital cardiac arrests (IHCAs) $(4,5)$. IHCAs often develop due to cardiac and pulmonary causes, and ICHs are also among the important causes of mortality and morbidity $(6,7)$. However, the necessity of computed tomography (CT) scan of the brain in patients with cardiac arrest is still unclear (8). The use of CT scan of the brain and thorax is recommended for the management of unexplained cardiac arrests in the guidelines (2). Intracranial pathologies detected in CT require many interventions in patients, including avoidance of antifibrinolytic, anticoagulant, and antiplatelet therapies and referral to neurology and critical care (5). Studies have shown that brain CT pathologies are considerably common in patients who are evaluated with cardiac arrest in the emergency department; therefore, further studies are needed to raise awareness on this issue (9). 
In this study, we aimed to investigate the incidence and the general characteristics of ICH detected by brain CT in patients who presented to our emergency department and developed IHCA, the role of resuscitation in these cases, and the outcomes.

\section{MATERIAL AND METHOD}

The study was initiated after obtaining approval from the Non-Interventional Clinical Research Ethics Committee of Eskişehir Osmangazi University (Date: 09.02.2021, Decision No: 2021-68-10). All procedures were carried out in accordance with the ethical rules and the principles of the Declaration of Helsinki.

The research was conducted as a single-center, retrospective study using data from patients who presented to the emergency department of a tertiary university hospital between January 1, 2011 and January 1, 2021. Our emergency department is a tertiary center, which was nationally accredited as a department. The list of patients who underwent CPR in the emergency department was accessed through the transaction codes and evaluated. An average of 110,000 patients are admitted annually, and adult ACLS trainings are regularly held (10). Care was provided in accordance with the Utstein protocol in all cardiac arrest patients (11). Patients who developed cardiac arrest during their follow-up in the emergency department were included in the study.. Brain CT scans of these patients were examined as before and after cardiopulmonary resuscitation (CPR). Those who underwent CT before CPR were primarily believed to have an intracranial pathology based on their clinical condition. However, CT scan and achieving return of spontaneous circulation (ROSC) after CPR require additional examination, as in OHCA patients.

Among the patients who developed IHCA and underwent CPR, those who had undergone brain CT scan were included in the study. Patients $<18$ years of age, those with traumatic arrests and OHCA, those who could not undergo CT scan, and pregnant patients were excluded from the study. Patients who were given fibrinolytic therapy without imaging during CPR in the emergency department were also excluded from the study.

Demographic data, vital parameters at presentation, Glasgow Coma Scale at presentation, presence of hemorrhage on brain CT scan, emergency department outcomes, hospitalization periods, and hospitalization outcomes as well as modified Rankin scale (mRS) scores were recorded. The hemorrhage has been investigated in the medical records and the presence of the hemorrhage has been evaluated by emergency physicians.

\section{Statistical Analysis}

Continuous data were presented as mean \pm standard deviation. Categorical data were given as percentage (\%). Shapiro-Wilk test was used to investigate the normality of the distributed data. For comparison of groups that do not conform to normal distribution, Mann-Whitney $\mathrm{U}$ test was utilized in cases where the number of groups was two. Pearson's Chi-Square and Pearson's Exact Chi-Square analyses were employed for the analysis of the cross tables created. IBM SPSS Statistics 21.0 (IBM Corp. Released 2012. IBM SPSS Statistics for Windows, Version 21.0. Armonk, NY: IBM Corp.) software was used to perform the analyses. The criterion for statistical significance was accepted as $\mathrm{p}<0.05$.

\section{RESULTS}

Among the patients who were brought to the emergency department owing to non-traumatic cardiac arrest or who developed cardiac arrest in the emergency department, 294 underwent CT scan of the brain. Of these patients, 173 experienced IHCA in the emergency department, and the evaluation was made using them. Intracranial bleeding was detected in $20(11.6 \%)$ of the 173 patients comprising the study group. Of these 20 patients, 10 were women. The demographic characteristics, presenting complaints, and vital signs of the patients are listed in Table 1. Altered mental status and syncope are the major neurological symptoms and $\% 60$ of the $\mathrm{ICH}$ group has these initial complaints. Regarding the assessment of the vital parameters, since eight patients were found to have an arrest when they were taken on a stretcher to the emergency department, their vital parameters were not included in the statistical evaluation. Systolic blood pressure, diastolic blood pressure, and oxygen saturation were statistically significantly higher in the ICH group than in the others $(\mathrm{p}=0.003, \mathrm{p}=0.007$, and $\mathrm{p}=0.035$, respectively). Of the patients with intracranial bleeding, seven (35.0\%) were consistent with subdural hemorrhage, seven (35.0\%) with subarachnoid hemorrhage, and six $(30.0 \%)$ with intraparenchymal hemorrhage. There was no significant difference between the groups with and without ICH in terms of hospital outcomes. Of the 20 patients with $\mathrm{ICH}$, three were discharged from the hospital. Furthermore, it was observed that two of these three patients were discharged with an $\mathrm{mRS}$ of 5 and one with an $\mathrm{mRS}$ of 4 .

In the evaluation of the timing of CT scan and CPR, it was found that $16(80.0 \%)$ of the patients with hemorrhage underwent CT scan prior to CPR, and this was found to be statistically significant ( $p<0.001)$. Emergency department outcomes, hospital outcomes, and lengths of hospital stay are presented in Table 2. 


\begin{tabular}{|c|c|c|c|}
\hline & $\begin{array}{c}\mathrm{ICH}+ \\
\mathrm{n}: 20\end{array}$ & $\begin{array}{l}\text { ICH - } \\
\text { n: } 153\end{array}$ & p-value \\
\hline Age, years [IQR] & $70.50[64.25-78.00]$ & $73.40[64.00-81.00]$ & 0.610 \\
\hline Female $\mathrm{n}(\%)$ & $10(50.0 \%)$ & $71(46.4 \%)$ & 0.762 \\
\hline Complaint & & & 0.033 \\
\hline Dyspnea, n (\%) & $1(5.0 \%)$ & $56(36.6 \%)$ & \\
\hline Angina pectoris, $\mathrm{n}(\%)$ & 0 & $2(1.3 \%)$ & \\
\hline Altered mental status, n (\%) & $10(50.0 \%)$ & $30(19.6 \%)$ & \\
\hline Loss of appetite, $\mathrm{n}(\%)$ & $6(30.0 \%)$ & $49(32.0 \%)$ & \\
\hline Syncope, n (\%) & $2(10.0 \%)$ & $8(5.2 \%)$ & \\
\hline Abdominal and back pain, $\mathrm{n}(\%)$ & $1(5.0 \%)$ & $8(5.2 \%)$ & \\
\hline \multicolumn{4}{|l|}{ Vital Signs } \\
\hline SBP, mmHg [IQR] & $150.00[92.50-177.50]$ & $100.00[80.00-130.00]$ & 0.001 \\
\hline $\mathrm{DBP}, \mathrm{mmHg}$ [IQR] & $75.00[60.00-100.00]$ & $60.00[50.00-80.00]$ & 0.003 \\
\hline Pulse rate[IQR] & $102.00[80.00-123.50]$ & $104.00[78.75-127.25]$ & 0.929 \\
\hline $\mathrm{SpO}_{2}, \%[\mathrm{IQR}]$ & $91.50[83.50-94.75]$ & $82.50[72.00-92.00]$ & 0.016 \\
\hline Respiratory rate, [IQR] & $21.00[20.00-24.00]$ & $24.00[20.00-30.00]$ & 0.088 \\
\hline GCS, [IQR] & $7.00[3.25-13.75]$ & $12.00[7.00-14.00]$ & 0.107 \\
\hline
\end{tabular}

\begin{tabular}{|c|c|c|c|}
\hline & $\begin{array}{c}\mathrm{ICH}+ \\
\mathrm{n}: 20\end{array}$ & $\begin{array}{l}\text { ICH - } \\
\text { n: } 153\end{array}$ & p-value \\
\hline CT timing & & & $<0.001$ \\
\hline Before CPR, n (\%) & $16(80.0 \%)$ & $57(37.3 \%)$ & \\
\hline After CPR, n (\%) & $4(20.0 \%)$ & $96(62.7 \%)$ & \\
\hline Emergency outcome & & & 0.478 \\
\hline Admission, $\mathrm{n}(\%)$ & $16(80.0 \%)$ & $111(72.5 \%)$ & \\
\hline Exitus, n (\%) & $4(20.0 \%)$ & $42(27.5 \%)$ & \\
\hline Hospital outcome & & & 0.715 \\
\hline Discharge, n (\%) & $3(15.0 \%)$ & $18(11.8 \%)$ & \\
\hline Exitus, n (\%) & $17(85.0 \%)$ & $135(88.2 \%)$ & \\
\hline $\begin{array}{l}\text { Length of stay, hours } \\
\text { [IQR] }\end{array}$ & $\begin{array}{c}23.00 \\
{[4.50-66.00]}\end{array}$ & $\begin{array}{c}9.50 \\
{[3.00-25.00]}\end{array}$ & 0.072 \\
\hline
\end{tabular}

Computed tomography scan status of the patients before and after the development of cardiac arrest was examined. The number of patients who developed cardiac arrest and subsequently achieved ROSC and underwent CT scan of the brain was 100 . It was determined that four patients in this group had intracranial hemorrhage. Of these patients, two had subdural hemorrhage, one had intraparenchymal hemorrhage, and one had subarachnoid hemorrhage. While the patient with intraparenchymal hemorrhage was using warfarin, the patient with subarachnoid hemorrhage (SAH) was using acetylsalicylic acid. The other two patients were not using any antiaggregants or anticoagulants. Demographic data comparing the characteristics of these four patients with the other 96 patients, vital parameters, and hospital outcome information are presented in Table 3. The mRS scores of the groups with and without intracranial hemorrhage were found to have a median value of six in both groups.
Table 3. General evaluation of brain CT in patients with return of spontaneous circulation after CPR.

\begin{tabular}{|c|c|c|c|}
\hline & $\begin{array}{l}\text { After CPR } \\
\text { CT ICH+ } \\
\mathrm{n}: 4\end{array}$ & $\begin{array}{l}\text { After CPR CT } \\
\text { ICH- } \\
\text { n: } 96\end{array}$ & p-value \\
\hline Age, years [IQR] & $\begin{array}{c}77.50 \\
{[72.50-81.00]}\end{array}$ & $\begin{array}{c}72.00 \\
{[62.50-80.00]}\end{array}$ & 0.268 \\
\hline Female, n (\%) & $1(25.0 \%)$ & $41(42.7 \%)$ & 0.637 \\
\hline Complaint & & & 0.283 \\
\hline Dyspnea, n (\%) & 0 & $48(50 \%)$ & \\
\hline Angina pectoris, $\mathrm{n}(\%)$ & 0 & $2(2.1 \%)$ & \\
\hline $\begin{array}{l}\text { Altered mental status, } \\
\mathrm{n}(\%)\end{array}$ & $1(25.0 \%)$ & $9(9.4 \%)$ & \\
\hline Loss of appetite, $\mathrm{n}(\%)$ & $2(50.0 \%)$ & $27(28.1 \%)$ & \\
\hline Syncope, $\mathrm{n}(\%)$ & $1(25.0 \%)$ & $6(6.3 \%)$ & \\
\hline $\begin{array}{l}\text { Abdominal and back } \\
\text { pain, } \mathrm{n}(\%)\end{array}$ & 0 & $4(4.2 \%)$ & \\
\hline \multicolumn{4}{|l|}{ Vital Signs } \\
\hline $\mathrm{SBP}, \mathrm{mmHg}[\mathrm{IQR}]$ & $\begin{array}{c}120.00 \\
{[77.75-190.00]}\end{array}$ & $\begin{array}{c}100.00 \\
{[70.00-130.00]}\end{array}$ & 0.404 \\
\hline DBP, mmHg [IQR] & $\begin{array}{c}75.00 \\
{[50.00-115.00]}\end{array}$ & $\begin{array}{c}60.00 \\
{[40.00-80.00]}\end{array}$ & 0.255 \\
\hline Pulse rate, $[\mathrm{IQR}]$ & $\begin{array}{c}96.00 \\
{[68.50-140.00]}\end{array}$ & $\begin{array}{c}108.00 \\
{[80.00-130.00]}\end{array}$ & 0.777 \\
\hline $\mathrm{SpO}_{2}, \%[\mathrm{IQR}]$ & $\begin{array}{c}84.00 \\
{[53.75-94.00]}\end{array}$ & $\begin{array}{c}75.00 \\
{[70.00-88.00]}\end{array}$ & 0.552 \\
\hline Respiratory rate, [IQR] & $\begin{array}{c}17.00 \\
{[11.00-29.00]}\end{array}$ & $\begin{array}{c}28.00 \\
{[21.00-32.00]}\end{array}$ & 0.107 \\
\hline GCS, [IQR] & $\begin{array}{c}5.00 \\
{[3.00-13.00]}\end{array}$ & $\begin{array}{c}12.00 \\
{[6.00-14.00]}\end{array}$ & 0.317 \\
\hline Emergency outcome & & & 0.999 \\
\hline Admission, $\mathrm{n}(\%)$ & $4(100 \%)$ & $79(82.3 \%)$ & \\
\hline Exitus, n (\%) & 0 & $17(17.7 \%)$ & \\
\hline Hospital outcome & & & 0.999 \\
\hline Discharge, n (\%) & 0 & $10(10.4 \%)$ & \\
\hline Exitus, n (\%) & $4(100 \%)$ & $86(89.6 \%)$ & \\
\hline $\begin{array}{l}\text { Length of stay, hours } \\
\text { [IQR] }\end{array}$ & $\begin{array}{c}17.50 \\
{[5.25-29.75]}\end{array}$ & $\begin{array}{c}10.00 \\
{[4.00-22.00]}\end{array}$ & 0.524 \\
\hline \multicolumn{4}{|c|}{$\begin{array}{l}\text { ICH: Intracranial hemorrhage, IQR: Interquartile range, SBP: Systolic blood pressure, } \\
\text { DBP: Diastolic blood pressure, SpO: Oxygen saturation, GCS: Glasgow coma scale, } \\
\text { CT: Computerized tomography, CPR: Cardiopulmonary resuscitation, }\end{array}$} \\
\hline
\end{tabular}




\section{DISCUSSION}

In our study, the median age was 72.00 [64.00-80.00] years. In a study by Wallmuller et al. in which IHCA was examined, the mean age was found to be 64 (4). In a study by Naples et al. examining the brain CT scans of the patients who underwent CPR, the mean age was 58.5 and $60 \%$ of the study participants were men (9). In our study, the proportion of male participants was found to be $53.1 \%$. The difference between our demographic data and the literature could be due to the fact that the study involved different sociodemographic groups.

In a study conducted by Kürkciyan et al., SAH was shown to be the cause of cardiac arrest in $4 \%$ of the patients (12). Shin et al. investigated ICH in patients with OHCA and found that ICH occurred at a rate of $11.4 \%$ in these patients (13). Naples et al. determined the rate of ICH to be $18 \%$ in their study (9). In a work by Cocchi et al. in which the role of brain CT scan after cardiac arrest was examined, this rate was found to be $11.7 \%$ (5). Similar to the literature, the incidence of $\mathrm{ICH}$ in patients who underwent CT scan of the brain was found to be $11.6 \%$ in our study. Wallmuller et al. estimated the rate of $\mathrm{ICH}$ to be $1 \%$ in their study on IHCA (4). However, this difference may be due to the fact that the study by Wallmuller et al. included only patients in whom ROSC was successfully achieved.

Inamasu et al. found pre-cardiac arrest neurological symptoms at a rate of $5 \%$ in their study (14). In our study, $60 \%$ of the patients with ICH had neurological symptoms prior to cardiac arrest, and this was statistically significant. This variation may be due to the difference in the location and the amount of bleeding.

In the present study, when the vital parameters were examined, higher blood pressure was observed in those with ICH than in those without ICH, which was statistically significant. It is considered that this may be a result of increased susceptibility to ICH in patients with high blood pressure and the neuroendocrine mechanisms occurring after ICH (15). In a study by Shin et al., the $\mathrm{SPO}_{2}$ value was found to be lower in patients with ICH than in those without ICH. Conversely, in our study, the $\mathrm{SPO}_{2}$ value was found to be higher in patients with $\mathrm{ICH}$. This difference may be due to the fact that Shin et al. examined OHCA cases, but the present study included only IHCA cases; thus, the vital parameters at presentation could be measured.

In our study, ICH was more common in patients who underwent CT scan prior to CPR. The reason for this observation may be that the symptoms of the patients could be evaluated before CPR and imaging requested for preliminary diagnosis.
In a study performed by Shin et al. in patients with OHCA, it was found that no patients with ICH had favorable neurological outcomes (13). Similarly, Gelber et al. found that the survival rate of patients with $\mathrm{ICH}$ was $33 \%$ in OHCA and that no patients had good neurological survival (16). In the present study, no significant difference was observed between those with and without ICH in terms of discharge and survival, which may be due to the fact that our study consisted of patients with IHCA and that they were resuscitated early.

When the presenting complaints of the patients were examined, it was found that ICH was more common in the brain CT scan of the patients with an altered state of consciousness and impaired general condition. Thus, early evaluation of the patients for ICH when they present to the emergency department with the complaints would be useful.

In our study, we found $\mathrm{ICH}$ at a rate of $4 \%$ in patients in whom ROSC was achieved after CPR and who underwent brain CT scan due to cardiac arrest of unknown cause. Similarly, this rate was found to be $3.5 \%$ in a study by Gelber et al., which examined the incidence of ICH in cases with OHCA (16). We believe that this rate is similar in cases with OHCA and IHCA. Taking into account that some treatments applied during CPR in cases with IHCA would increase the likelihood of ICH, we believe that this rate of $4 \%$ is at a considerable level. Therefore, it would be appropriate to evaluate the patients using $\mathrm{CT}$ scan of the brain as soon as ROSC is achieved in those with cardiac arrest of unknown cause.

\section{Limitations}

The most important limitation of our study is that it was single-centered and retrospective. In addition, we are not able to provide accurate information about the correct rates since patients with ROSC were mainly evaluated. We believe that further studies are needed on these rates since we did not have the chance to perform autopsy or postmortem CT. In our study, we did not find any patient who received fibrinolytic therapy and had bleeding, but we were unsure about whether they had intracranial hemorrhage at the center in which they were hospitalized.

\section{CONCLUSION}

In this study, we found the rate of ICH in patients who developed IHCA to be $11 \%$. We believe that this rate is considerably high. Since ICH warrants changes in the treatment and management of patients, its presence should be excluded with brain CT scan in cases with cardiac arrest of unknown cause, as stated 
in the guidelines. It would be a logical choice to use CT scan of the brain, which can be easily accessed in the emergency departments, in patients with ROSC. This should be the standard approach whenever the procedure would not cause any delay in treatment and/ or while simultaneously initiating treatment even if the cause is determined by $5 \mathrm{H}-5 \mathrm{~T}$. When all of these factors are taken into consideration, we believe that the algorithms for ICH should be revised. More detailed studies are needed for cases with IHCA of unknown cause, especially if altered state of consciousness and high blood pressure are detected.

\section{ETHICAL DECLARATIONS}

Ethics Committee Approval: The study was initiated after obtaining approval from the Non-Interventional Clinical Research Ethics Committee of Eskişehir Osmangazi University (Date: 09.02.2021, Decision No: 2021-68-10).

Informed Consent: Because the study was designed retrospectively, no written informed consent form was obtained from patients.

Referee Evaluation Process: Externally peer-reviewed.

Conflict of Interest Statement: The author(s) declared no potential conflicts of interest with respect to the research, authorship, and/or publication of this article.

Financial Disclosure: The authors have not declared a specific grant for this research from any funding agency in the public, commercial or not-for-profit sectors.

Author Contributions: All of the authors declare that they have all participated in the design, execution, and analysis of the paper, and that they have approved the final version.

\section{REFERENCES}

1. Soar J, Böttiger BW, Carli P, et al. European resuscitation council guidelines 2021: adult advanced life support. Resuscitation 2021; 161: 115-51.

2. Part 3: Adult Basic and Advanced Life Support: 2020 American Heart Association Guidelines for Cardiopulmonary Resuscitation and Emergency Cardiovascular Care / Circulation [Internet]. [cited 2021 Apr 22]. Available from: https://www.ahajournals.org/ doi/10.1161/CIR.0000000000000916

3. Skrifvars MB, Parr MJ. Incidence, predisposing factors, management and survival following cardiac arrest due to subarachnoid haemorrhage: a review of the literature. Scand J Trauma Resusc Emerg Med 2012; 20: 75.

4. Wallmuller C, Meron G, Kurkciyan I, Schober A, Stratil P, Sterz F. Causes of in-hospital cardiac arrest and influence on outcome. Resuscitation 2012; 83: 1206-11.

5. Cocchi MN, Lucas JM, Salciccioli J, et al. The role of cranial computed tomography in the immediate post-cardiac arrest period. Intern Emerg Med 2010; 5: 533-8.

6. Andersen LW, Holmberg MJ, Berg KM, Donnino MW, Granfeldt A. In-Hospital cardiac arrest. JAMA 2019; 321: 1200-10.
7. Schluep M, Gravesteijn BY, Stolker RJ, Endeman H, Hoeks SE. One-year survival after in-hospital cardiac arrest: a systematic review and meta-analysis. Resuscitation 2018; 132: 90-100.

8. Akinboro $\mathrm{O}$, Olorunfemi $\mathrm{O}$, Jesmajian $\mathrm{S}$, Ovbiagele $\mathrm{B}$. Epidemiology and outcomes of in-hospital cardiac arrest after stroke in the United States. Neurology 2016; 86: P1.222

9. Naples R, Ellison E, Brady WJ. Cranial computed tomography in the resuscitated patient with cardiac arrest. Am J Emerg Med 2009; 27: 63-7.

10. Algorithms for Advanced Cardiac Life Support 2021 [Internet]. [cited 2021 Mar 22]. Available from: https://www.acls.net/aclsalg. htm

11. Nolan JP, Berg RA, Andersen LW, et al. Cardiac Arrest and Cardiopulmonary Resuscitation Outcome Reports: Update of the Utstein Resuscitation Registry Template for In-Hospital Cardiac Arrest: A Consensus Report From a Task Force of the International Liaison Committee on Resuscitation (American Heart Association, European Resuscitation Council, Australian and New Zealand Council on Resuscitation, Heart and Stroke Foundation of Canada, InterAmerican Heart Foundation, Resuscitation Council of Southern Africa, Resuscitation Council of Asia). Circulation 2019; 140: 746-57.

12.Kürkciyan I, Meron G, Sterz F, et al. Spontaneous subarachnoid haemorrhage as a cause of out-of-hospital cardiac arrest. Resuscitation 2001; 51: 27-32.

13. Shin J, Kim K, Lim YS, et al. Incidence and clinical features of intracranial hemorrhage causing out-of-hospital cardiac arrest: a multicenter retrospective study. Am J Emerg Med 2016; 34: 2326-30.

14. Inamasu J, Miyatake $S$, Tomioka $H$, et al. Headache, cardiac arrest, and intracranial hemorrhage. J Headache Pain 2009; 10: 357-60.

15.Lattanzi S, Silvestrini M. Blood pressure in acute intra-cerebral hemorrhage. Ann Transl Med 2016; 4: 320.

16. Gelber J, Montgomery ME, Singh A. A prospective study of the incidence of intracranial hemorrhage in survivors of out of hospital cardiac arrest. Am J Emerg Med 2021; 41: 70-2. 